\title{
Affects of the Cold Water Pipe Depth in Ocean Thermal Energy Converter Plants with respect to Power Generation Efficiency.
}

Helia Danielle Giordani ${ }^{1, *}$, Matheus Lages ${ }^{2}$, Miguel Medina ${ }^{3}$ and Jade Tan-Holmes ${ }^{4}$

Faculty of Science, UTS, P.O. Box 123, Australia;

${ }^{1}$ Email: HeliaDanielle.GiordaniBarreira@student.uts.edu.au

${ }^{2}$ Email: Matheus.CarvalhoLagesDiniz-1@student.uts.edu.au

${ }^{3}$ Email: MiguelFernando.deMattosMedinaJunior@student.uts.edu.au

${ }^{4}$ Email: Jade.J.Tan-Holmes@student.uts.edu.au

* Author to whom correspondence should be addressed; Jade.J.Tan-Holmes@student.uts.edu.au

Received: 25/5/2015 / Accepted: 29/5/2015 / 1/6/2015:

\begin{abstract}
The Ocean provides an extensive renewable energy source. It is the exploitation of the thermal gradient between the warmed surface water and the deep cold water. A heat engine was developed to use the surface water as a heat source and the deep water as a cold source in order to convert thermal energy into mechanical energy and generate electricity. This process is called Ocean Thermal Energy Conversion (OTEC). This paper presents the three different types of OTEC power plants: closed-cycle, open-cycle and hybrid-cycle, showing real and conceptual examples of each. All three systems are analyzed in terms of gross power, net power, efficiency and size. Furthermore, the depth of the cold water pipe is discussed and related to the net power generation of the OTEC plant. The power generation efficiency of the plant increases as the gross power production increases. This is due to the depth of the cold water pipe and amount of power used by the cold water pipe pump.
\end{abstract}

Keywords: Ocean Thermal Energy Converter; OTEC; Cold Water Pipe; Thermodynamics; Power Production; Thermal Gradient; Renewable Energy.

Copyright: (C) 2015 by the authors. This article is distributed under the terms and conditions of the Creative Commons Attribution license (https://creativecommons.org/licenses/by/4.0/).

DOI: http://dx.doi.org/10.5130/pamr.v2i0.1395

PAM Review is a Student Journal from UTS ePRESS showcasing outstanding UTS student works 


\section{Introduction}

Man must not live on the planet he inhabits, but live with it. For this half of the twenty-first century an electricity demand of $10^{28}\left(2.7 \times 10^{5} \mathrm{TWh}\right)$ is expected. It is known that three-quarters of the Earths surface is covered by water. So, out of a total of $600 \times 10^{6} \mathrm{TWh}$ of solar energy that hits the Earth annually, $120 \times 10^{6}$ TWh are absorbed and stored by the oceans in the form of thermal, chemical, mechanical and biochemical energy (the rest being mainly reflected). To get an idea of the proportion of this energy in the overall balance, the first three meters of the surface layer of the ocean stores more solar energy than the whole atmosphere combined, including wind (Netto 2009).

One of the oceans major renewable energy sources is the exploitation of the thermal gradient between the surface and the deep water, which has the potential to produce about 40 billion MW, while the exploitation of salinity gradients, marine currents, tides, waves and biomass potential utilization (assuming an efficiency of photosynthesis 2\%) together have the potential to produce 1.41 billion MW. So the sea, although mechanical in appearance, is significantly more thermal in terms of potential energy. The ocean (like the atmosphere), despite appearances, is full of potential thermal energy.

The mechanical energy dissipated in the ocean (in its various forms) has a maximum of $0.1 \%$ of the energy that the sea delivers to the atmosphere in the evaporation process. So marine mechanical energy is only a negligible by-product compared to the heat flow from the deep layers of the ocean. The thermal gradient between the surface and depths of the ocean is by far the main usable resource exceeding the 32 billion estimated for consumption of mankind in this new Millennium (Netto 2009).

The surface layer of the ocean (50 to 100 meters deep) is a thermal power reserve available for man, which is nothing more than stored solar energy. Those who criticize solar energy for the fact that it is difficult to store because it is not constant and regular, forget that the ocean (72\% of the globe's surface) has its main function as geophysics, which is exactly that of stored solar energy. Tropical and equatorial zones are a major reservoir of this energy. Unfortunately, this stored energy has a relatively low temperature (about $25^{\circ} \mathrm{C}$ ). However, what characterizes the ocean is that, next to this immense "heat source" at $25^{\circ} \mathrm{C}$, there is a virtually inexhaustible source of cold water ( $4^{\circ} \mathrm{C}$ or less). D'Arsonval proposed in 1881 to mount a heat engine using the ocean surface water as heat source $\left(25^{\circ} \mathrm{C}\right)$ and deep water as a cold source. This led to the practice of Ocean Thermal Energy Conversion.

An Ocean Thermal Energy Converter (OTEC) power plant is a heat engine that produces electricity. A Heat engine refers to a device that uses heat transfer to do work; in other words, thermal energy is converted to mechanical energy via a heat flow from a hot reservoir to a cold reservoir (Schulte 2015). A heat engine turns heat in a cyclic process from a hot reservoir into work. However, he cost is "wasted heat". This process is based on the second law of thermodynamics, which states that the heat cannot flow spontaneously from a body of lower temperature to a body of higher temperature. As a result, for the reverse flow to be possible, an external agent is required to perform work on the system. In addition, it is impossible to build a heat engine operating on a thermodynamic cycle, which converts one hundred percent of the heat put into the system into work. The sun warmed surface water of the oceans is the heat source of an OTEC plant and the deep cold water is the cold source. 
OTEC plants operate on a reversible thermodynamic cycle called the Rankine Cycle (see appendix A), which is a variation of the Carnot Cycle. Even though the maximum efficiency is obtained through the Carnot Cycle, the ideal cycle for the OTEC technology is the Rankine. The reason for this is not only to avoid damages to the turbines but also efficiency issues of the pumps (Netto 2009).

There are three different types of OTEC devices currently in construction, based on three different types of cycles. They include a closed-cycle, open-cycle and hybrid-cycle. These three systems are described below.

\section{Closed Cycle Ocean Thermal Energy Converters}

Closed-cycle ocean thermal energy converters utilize fluids with a low boiling point, such as ammonia, to spin a turbine, which generates electrical energy. This fluid is called the working fluid (Energy.gov, 2015). The diagram below illustrates the key components of the closed-cycle system used by all closed-cycle system OTEC, which is then followed by a brief description of the process.

Heat from solar radiation heats the surface of the ocean where the OTEC device is implanted. This warm surface water is pumped through a heat exchanger (evaporator), which contains the working fluid. Because of the low boiling point of the working liquid, the relatively high temperature of the warm seawater is enough to vaporize it. See in figure 1 that as the working fluid leaves the evaporator, it is released as working fluid vapor. The expanding vapor then travels through a pipe and rotates a turbine.

Figure 1. Principal features of a closed-cycle ocean thermal energy system (En.openei.org, 2015).

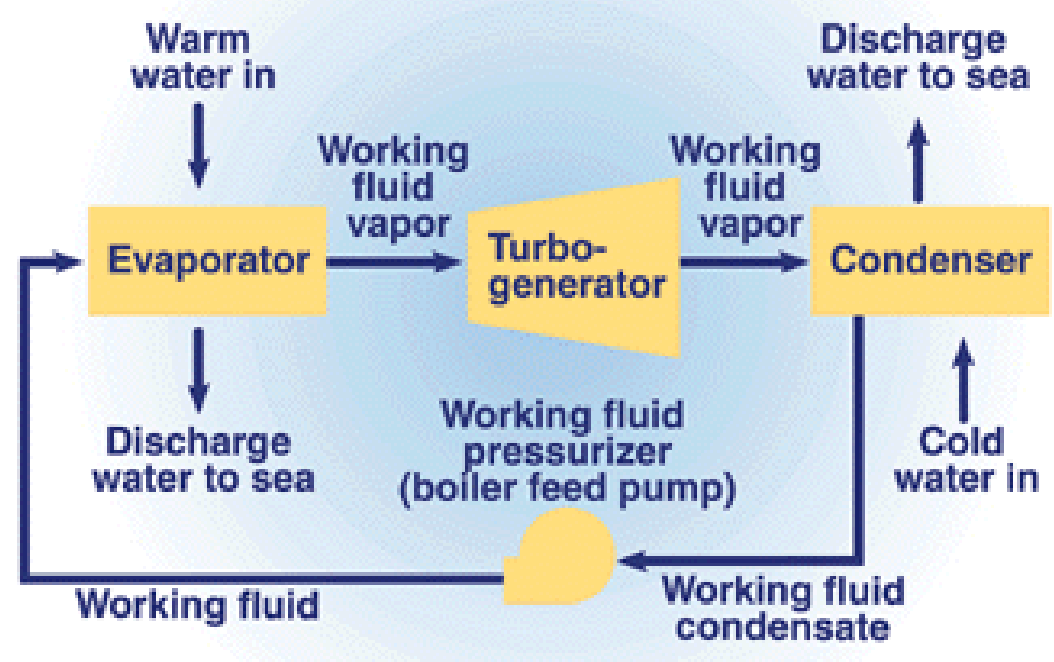


The turbine is connected to an electrical grid, and the mechanical rotation of the turbine blades is what produces electrical energy. The working fluid vapor then continues to travel through the pipe until it arrives at the condenser. This is where cold seawater from the depths of the ocean is pumped through another heat exchanger, causing the working fluid vapor to liquefy once more. The working fluid, now liquid, is recycled back into the system via a pump and the process is repeated (Energy.gov, 2015).

\section{Power Production}

The net power of the OTEC device is the net power of the Rankine cycle minus the power that is recycled back into the system to power the OTEC. This includes the power used for pumping the cold and hot seawater into their corresponding heat exchangers:

$$
\text { (1) } \quad P_{N}=P_{R}-P_{C S}-P_{W S}
$$

Where $P_{R}$ is the net power generated by the Rankine cycle, $P_{C S}$ is the power needed to pump cold seawater into the condenser and $P_{w s}$ is the power needed to pump the warm seawater from the ocean surface into the evaporator (Avery and Wu, 1994).

\section{Working Fluids}

The selection of the working fluid is very important, as the Rankine cycle is dependent on the fluid changing phase at specific ocean temperatures (between surface and deep sea level). This means it is necessary for the working fluid to have a low boiling point, such as ammonia (boiling point $=-33^{\circ} \mathrm{C}$ ). Other examples of working fluids include propane, butane and carbon dioxide (Hagen, 1975).

\section{Open Cycle Ocean Thermal Energy Converters}

Open cycle OTEC systems are similar to closed-cycle systems, the difference being that they utilize seawater as the working fluid. In this type of OTEC, the seawater is released after use, not returning to the starting point of the cycle. Hence the name open cycle (Masutani \& Takahashi, 2001). Below is a schematic of the key components of the open-cycle system, used by all open-cycle OTEC plants, which is then followed by a brief description of the process. 
Figure 2: OTEC system of open cycle and its major subsystems (Usvat Corporation Energy Department, 2014).

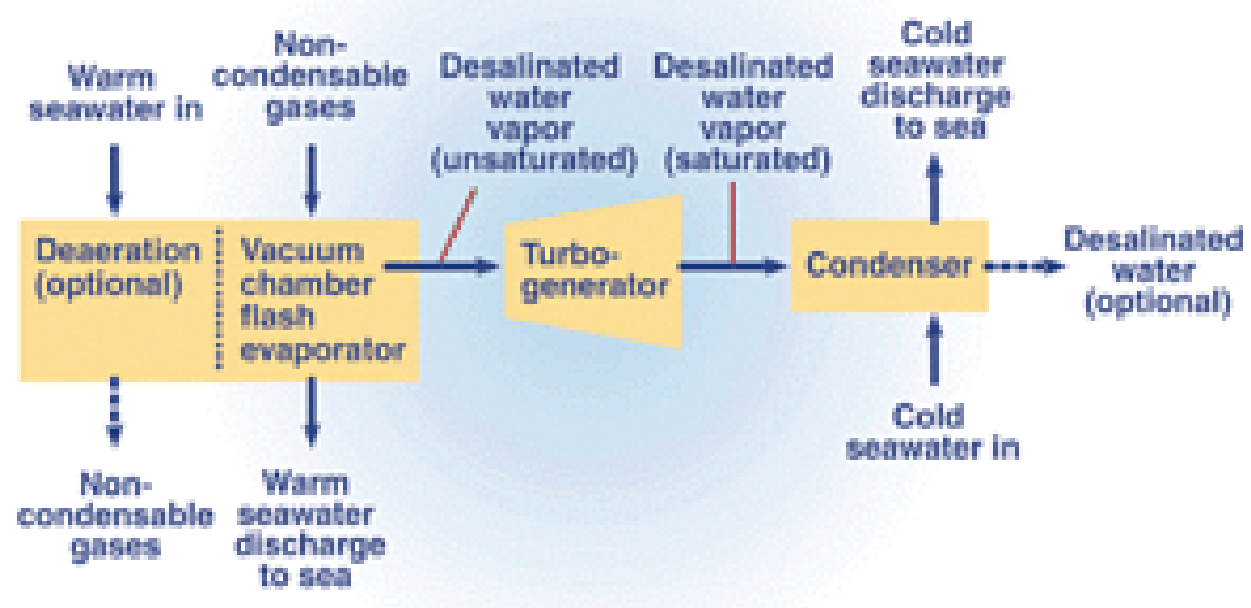

In the open cycle, warm seawater is pumped into a chamber in which the pressure is reduced by a vacuum pump to a low enough value to make water undergo a partial flash evaporation (rapid volume evaporation). The steam then expands through a low-pressure turbine that is connected to an electrical generator. After passing through the previous processes, the vapor is condensed in a similar chamber by cold seawater that is pumped from the deep ocean via a cold water pipe. Finally, the water is discharged into the ocean. However, instead of being condensed by direct contact with the cold seawater, the steam is directed to a heat exchanger cooled by cold seawater. In this case, the condensed water vapor becomes fresh water since the steam left most of its salt in the evaporation chamber at low pressure (Masutani \& Takahashi, 2001).

A key subsystem in this type of cycle is the flash evaporator that allows evaporation of seawater at low pressures. The conventional models such as the open channel flowing have thermodynamic performance between $70-80 \%$. A model called vertical-flow evaporator was developed, which is conveyed upward over a vertical pipe and forcibly sprayed out of the barrel through an exhaust jet. To increase the efficiency of the evaporator, the sprayed water may drop on screens that dissolve drops of water, improving the rate of evaporation. This type of evaporator reaches a thermodynamic performance of 90\% (Avery and Wu, 1994). 


\section{Hybrid Cycle Ocean Thermal Energy Converter}

As the name suggests, this cycle is a hybridization of the closed and open cycle OTEC's. This cycle is similar to the previously mentioned cycles in that:

1 - Like the open cycle, the hybrid cycle produces pure water. Therefore, this cycle makes the device significantly cheaper as it will produce desalinated water as well as electrical energy, providing two sources of income.

2 - Like the closed-cycle, it uses a working fluid (normally ammonia), so it will not have problems such as oxidation.

Like the previously mentioned cycles, hybrid OTEC's use water from the ocean surface, water from the bottom of the sea and a working fluid - normally ammonia. Once the warm water is pumped to the device it is evaporated in a low-pressure environment (a vacuum), thus only $0.5 \%$ of the water is transformed into steam. This steam is then condensed in the ammonia evaporator and now, desalinated, can be used as pure water. Once the ammonia has been transformed into vapour, it spins the turbine as it expands through the pipe. The cold water from the bottom of the ocean then condenses it back into liquid, before being recycled back through the system. Figure 3 shows a general hybrid cycle OTEC.

From the diagram, we can clearly see all the processes happening in a hybrid power plant. From the bottom left of the diagram, the warm water from the surface is pumped up and used to vaporize the ammonia. Once vaporized, the ammonia will pass by the turbine, forcing it

Figure 3. Heat and Mass Balance of a Pre-Commercial Hybrid OTEC plant (Clubdesargonautes.org, 2015).

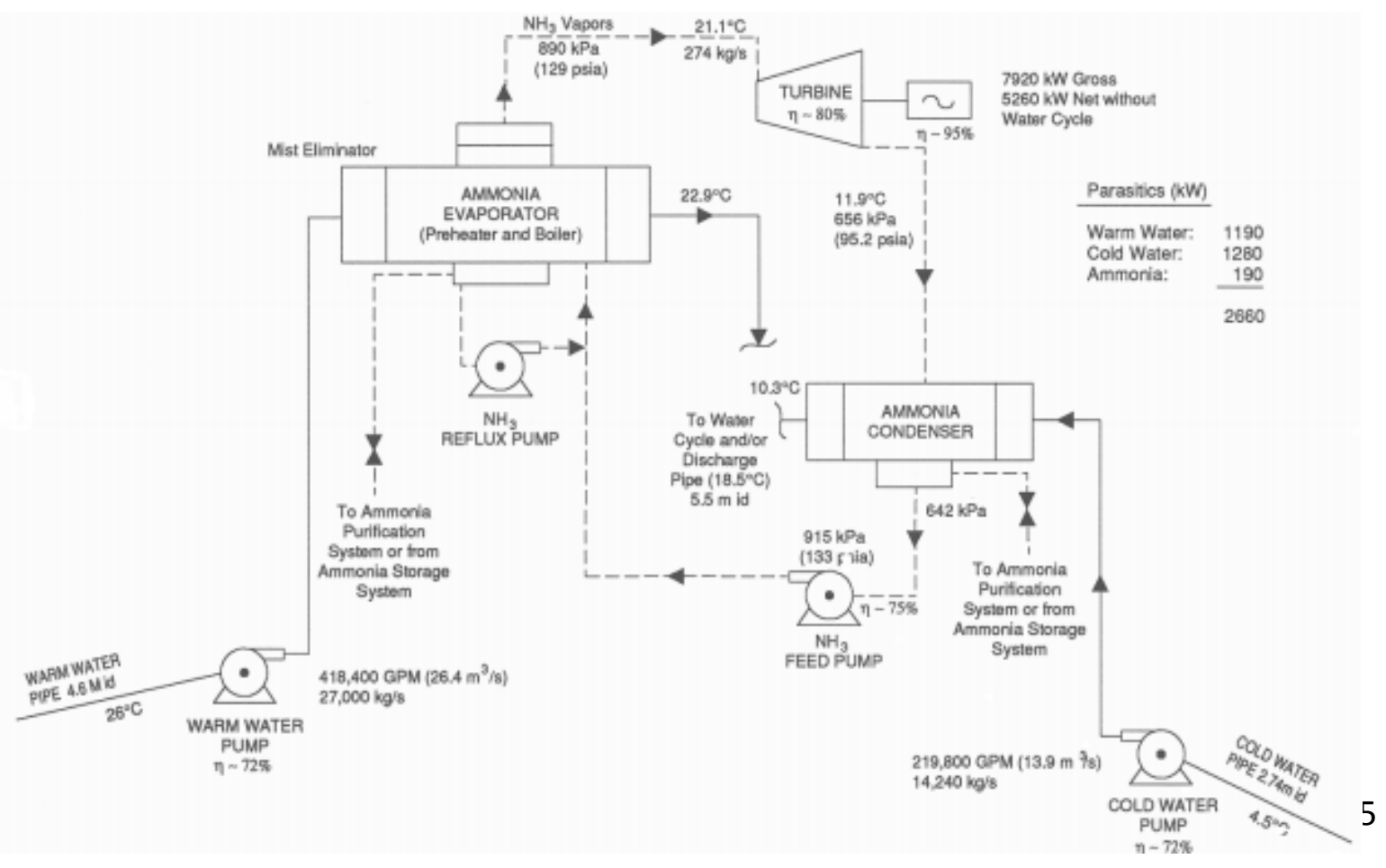


to spin. This in turn generates electricity. From the bottom right of the diagram the deep cold water is pumped up to condense the ammonia. Once liquid again, the ammonia travels to the evaporator to repeat the cycle. As we can see in the diagram, part of the ammonia is used to desalinate water.

This meta-study focuses on a common component of all three types of OTEC, the cold water pipe (CWP) that transports the cold water from the depths of the ocean to the condenser. In order to reach water of a low enough temperature, the CWP needs to reach a considerable depth (around $1000 \mathrm{~m}$ ) (Clubdesargonautes.org, 2015). This means that a substantial amount of the gross power being produced by the OTEC system is being used to power the cold water pipe pump to bring the deep water to the condenser, which is located near the surface. This meta-study investigates further the magnitude of this parasitic power, and whether it varies with the magnitude of the gross power output of the OTEC plant. Based on this investigation, it will be concluded whether larger or smaller scale plants are more efficient in terms of power production.

\section{Methodology}

In order to gain a thorough understanding of the topic (before any data was to be collected), a collection of textbooks, websites and lecture notes on thermal energy conversion and the previously mentioned cycles were studied and analyzed until a reasonable confidence was built. These textbooks were accessed via the UTS library website, and lecture notes presented by Dr. Jurgen Schulte, University of Technology Sydney. Once we were confident in our background knowledge of the topic, we began our search of specific examples of OTEC plants by searching for articles and journals on known OTEC systems. Databases accessed through the UTS library website (EBSCO, Elsevier and Access Science) proved unhelpful, as there were not any papers with specific examples of pre-existing or conceptual OTEC plants. Our main sources of information were websites and journal articles found on the web, many of which contained information about potential future development of OTEC plants.

Furthermore, textbooks accessed through the UTS library contained a lot of information relevant to our topic of interest. Two specific textbooks and numerous journal articles found on the web were analyzed and used as supporting documentation.

At first our aim was to include only real examples of pre-existing OTEC plants in this metastudy, however there were very limited real examples of OTEC plants, as not many OTEC plants have been constructed. In order to have a larger range of data to analyze, it was decided conceptual OTEC plants would be included as well. In regards to the conceptual OTEC plants, there were numerous examples available, however not all of them contained the information we were interested in i.e. the depth of the cold water pipe (CWP), or the amount of power used by the cold water pipe pump (CWPP). The available information on the CWP was what steered our selection of the conceptual examples of OTEC plants included in this meta-study. In addition, there was an unequal distribution of the different types of OTEC plants being designed in terms of the cycle being used, with the closed-cycle being the most popular design, followed by the hybrid cycle.

Listed below are eight examples of OTEC plants that have been chosen based on the constraints listed above. A description of each plant is presented below, followed by the power 
output of each system, which was collected from various sources listed above, and the overall efficiency of the plants (with respect to power generation), which we calculated based on the data presented.

The method we used to calculate the overall efficiency was by taking the net power generation and dividing it by the gross power generation:

$$
\text { (2) } \quad \eta=P_{N} / P_{G}
$$

This calculation gives an overall idea of the amount of power wasted, which will be referred to as parasitic power throughout this meta-study, in the processes of the OTEC plant, and the amount that goes toward electricity generation. Furthermore, where possible, the depth and power usage of the CWP were collected and analysed. It proved difficult to find examples of OTEC plants which listed both of these features, but a total of four examples of OTEC plants were obtained which provided both these pieces of information and found to be useful for identifying conclusions and trends.

From the collected data, it will be investigated whether efficiency is related to the magnitude of the gross power generation of the plant (large scale or small scale), and whether this efficiency value is due to the depth of the CWP.

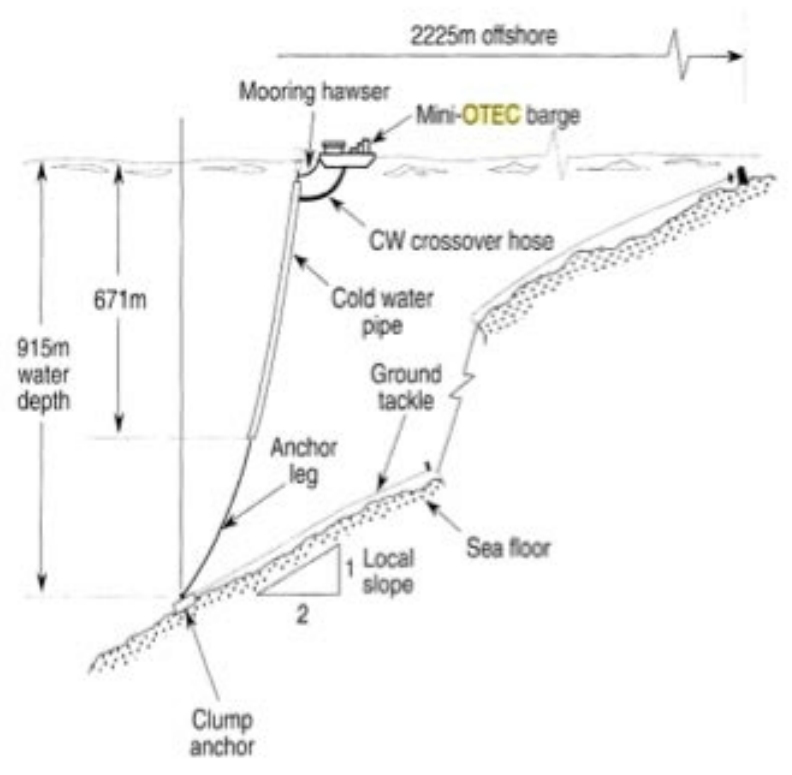

\section{U.S Mini-OTEC Program}

The U.S mini-OTEC program is an example of a real OTEC plant, completed in November 1979 after 4 months of successful operation offshore Kailuna-Kona Hawaii. The construction of the OTEC plant revolved around a closed-cycle system. The program was based at this particular place because of the warm and cold temperature gradient present in the water. A schematic of the design is shown below, illustrating the depth of the CWP at $671 \mathrm{~m}$ below the surface of the water. The working fluid used was ammonia (Avery and Wu, 1994).

The predicted gross power was up to $93 \mathrm{~kW}$; however, the small geared-down turbine possessed an efficiency of $56 \%$, so that only $53 \mathrm{~kW}$ of power was produced. The power used for pumping the cold deep water and warm surface water into corresponding heat exchangers consumed $35 \mathrm{~kW}$, meaning that, according to equation (1), the net output of the system was 18 kW.

Using equation (2), from this data we were able to calculate the over all efficiency of the U.S mini-OTEC plant to be $P_{N} / P_{G}=18 / 93=\sim 19 \%$ 


\section{Hawaii Land Based OTEC}

The land based OTEC experiment facility in Hawaii developed by L.A Vega, Ph.D, revolves around a hybrid cycle system. This real plant was designed and operated by a team led by Vega, 2002.

The turbine-generator was designed to produce an output of $210 \mathrm{~kW}$ for a $26^{\circ} \mathrm{C}$ warm surface water temperature and a deep-water temperature of $6^{\circ} \mathrm{C}$. A small fraction $(10 \%)$ of the steam produced was diverted to a surface condenser for the production of desalinated water. The experimental plant was successfully operated for six years (1993-1998). The highest production rates achieved were $255 \mathrm{~kW}$ (gross) with a corresponding net power of $103 \mathrm{~kW}$ and $0.4 \mathrm{I} \mathrm{s}-1$ of desalinated water. The gross output power achieved by the OTEC was $225 \mathrm{~kW}$, with

a corresponding net power of $103 \mathrm{~kW}$ (Vega 2002). From these values we were able to calculate the overall efficiency of power production to be $45.77 \%$.

\section{General Electric Corporation's Shelf Mounted Hawaii Site}

The General Electric (GE) OTEC design is a conceptual, closed-cycle system that was fabricated on a tower-mounted OTEC plant model. The plant was installed $2200 \mathrm{~m}$ offshore, and $100 \mathrm{~m}$ beneath the surface of the ocean. Its location is Kahe Point, Oahu, Hawaii. The plant utilizes underwater cables to carry the produced power to the Hawaiian Electric Company plant before being distributed to its customers.

The CWP reaches a depth of $670 \mathrm{~m}$, with a diameter of $8.5 \mathrm{~m}$. Cold water from the 8.5 $m$ diameter pipe enters an opening near the base of the tower, where it is rerouted to the condenser. The warm water used to pump into the evaporator is drawn from $15 \mathrm{~m}$ below the surface of the water, where it enters a manifold before being rerouted. In total, there are 4 condenser modules and 8 evaporator modules.

The gross power output of the system was $54.95 \mathrm{MW}$. However the power it takes for the hot and cold water to be pumped into the evaporators and condensers are $4.61 \mathrm{MW}$ and 9.89 MW respectively. The hotel and miscellaneous power added up to be $0.41 \mathrm{MW}$. This leaves a net power $40 \mathrm{MW}$ (Avery and $\mathrm{Wu}, 1994)$.

From these provided values, we can calculate the efficiency of the GE-OTEC plant using equation (2) to be $P_{N} / P_{G}=40 / 54.95=0.7279$. Therefore the GE tower mounted $40 \mathrm{MW}$ OTEC plant runs with an efficiency of $\sim 73 \%$

\section{Puerto Rico Electric Power Authority (PREPA)}

The conceptual idea for a closed-cycle OTEC which PREPA suggested consists of a towermounted 40 MW OTEC plant, located 2007 m offshore from Punta Tuna, Puerto Rico, at a depth of approximately $75 \mathrm{~m}$. A schematic of the PREPA-OTEC design is shown below, illustrating the depth of the CWP to be $1000 \mathrm{~m}$. 
Figure 5. Platform concept for PREPA OTEC plant in Puerto Rico, illustrating the depth of the CWP to be approximately $1000 \mathrm{~m}$ (Avery and Wu1994, p. 304).

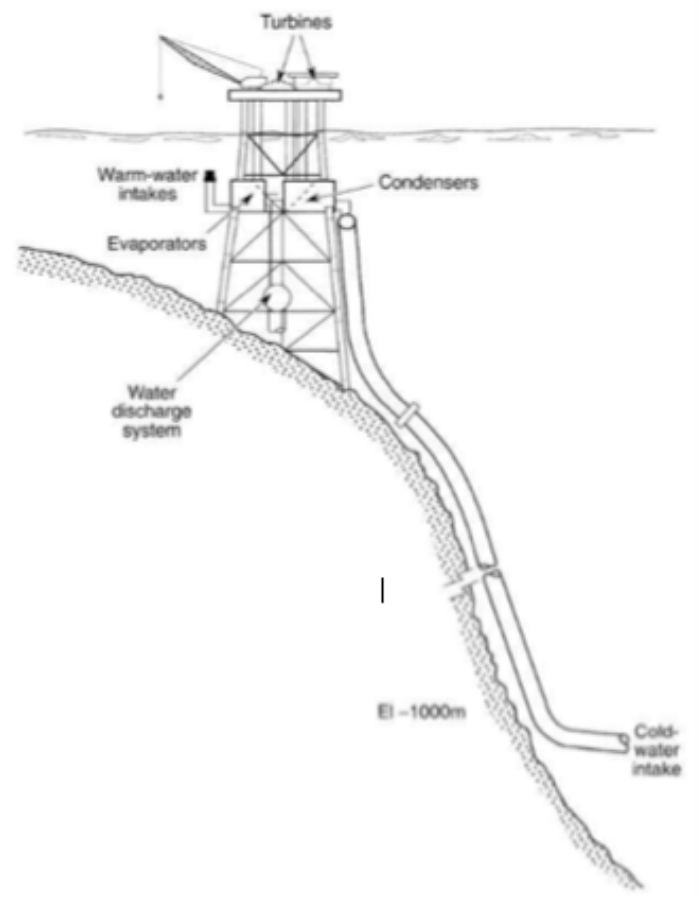

The entire plant is constructed from four $10 \mathrm{MW}$ modules, using shell-and-tube heat exchangers with ammonia as the working fluid. Both the evaporators and condensers sit at a depth of $15 \mathrm{~m}$ below the surface of the water. This was calculated to be an optimal balance between maximum depth to minimize wave forces, and location near the surface to maximize power output.

The system produces a gross power output of $53 \mathrm{MW}$. However because of the power needed to pump hot and cold water into the appropriate heat exchangers, the system is left with a net power of $40 \mathrm{MW}$ (Avery and Wu, 1994). Based on these figures, the efficiency of the PREPA tower-mounted OTEC design is calculated to be $75 \%$.

\section{C.B. Panchal Model}

The C.B. Panchal model is a hybrid-cycle design OTEC, and was suggested by C.B. Panchal, P.P. Pandolfini and W.H. Kumm in 2009. This design study focuses on the island market, where simultaneous production of power or compressed hydrogen, along with desalinated water, is shown to be competitive at a 10-MW plant size for a fuel price based on $\$ 50 /$ barrel crude oil price and a water price of $\$ 0.9 / \mathrm{m} 3$. This model had a CWP depth of 1000 $\mathrm{m}$.

The C.B. Panchal OTEC was estimated to produce a gross power output of $15307 \mathrm{~kW}$ and a net power output of $10014 \mathrm{~kW}$, with the power used by the CWPP being $2.5 \mathrm{MW}$ (Clubdesargonautes.org, 2015). From this information it can be calculated that the plant produced a power generation efficiency of $65 \%$. 


\section{Claude Ocean Thermal Energy Converter}

The concept of the Claude OTEC system was based on an open cycle, using the seawater as a working fluid, and included the construction of a prototype power plant off the Cuban coast. The open cycle OTEC has the potential to produce up to $25 \%$ more power than the closed cycle OTEC. This is because there is no loss in temperature in the exchange of heat from the tepid surface water to the working fluid in the open cycle process. The heat exchangers are the most expensive component of the plant in the closed cycle OTEC, and this cost can be saved if the Claude process (open-cycle) were used. In addition, the Claude cycle OTEC, offers others advantages like the production of desalinated and distilled water, relative immunity to biological fouling of surfaces and inexpensive turbines required.

However, there are also many technical problems in open cycle system, such as the turbine design. The reason for this weakness is that the components of the open cycle, including the turbine, need to be large enough to condition the large volume of steam because of the low system operating pressure. So a large conventional steam turbine will be necessary since only turbines of this type will have the ability to integrate the system.

Future research may circumvent these problems with alternative designs to establish the feasibility of constructing certain components in extremely large sizes. To determine the open cycle system's feasibility, a plant with a $100 \mathrm{MW}$ gross output was used. However because of the power that is necessary to pump hot and cold water into the appropriate heat exchangers, there was only a 45.7 MW net power output (Hagen, 1975). From these findings we were able to calculate the power generation efficiency of the Claude OTEC to be $\sim 46 \%$.

\section{Japanese Shore-Based OTEC}

The government of the Republic of Nauru along with engineers of the Tokyo Electric Power Co. and the Toshiba Corporation constructed a closed-cycle OTEC plant at a site on the island of Nauru in 1980.

The Nauru Island is a high coral reef surrounded by a lagoon of $50-150 \mathrm{~m}$ wide. Where the plant is located, the seabed is irregular up to $50 \mathrm{~m}$ deep from the coast and after that leans at an angle of 40-45 degrees up to $700 \mathrm{~m}$ deep. Although the seabed become porous further from the coast, the bearing capacity is sufficient for seabed emplacements. A schematic of the Japanese Shore-Based OTEC is shown below, demonstrating the depth of the CWP to be about $670 \mathrm{~m}$. 
Figure 3. Deployment procedure for the CWP installation for the Japanese Shore-Based OTEC on the Island of Nauru (Avery and Wu, 1993, p. 292).

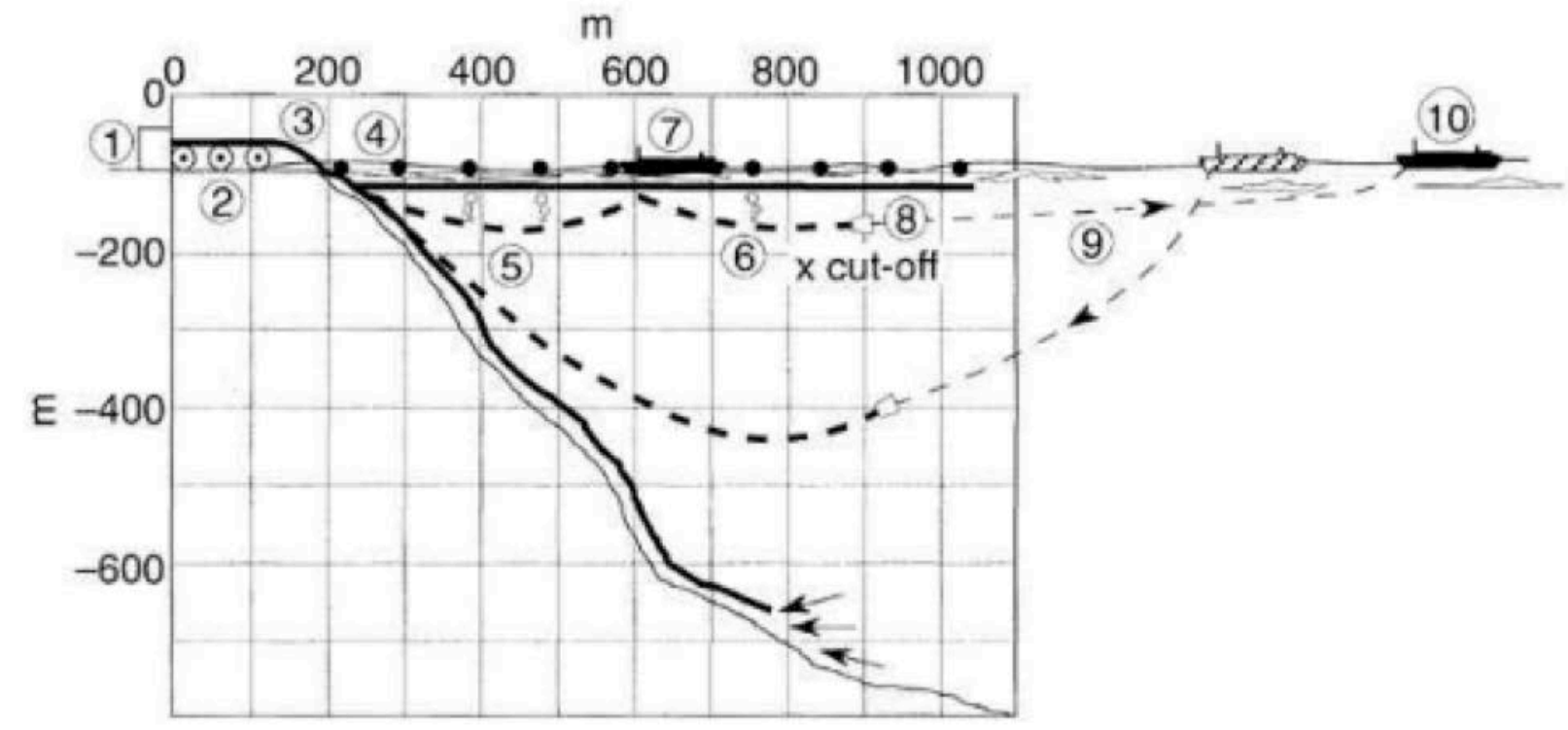

This plant was the first OTEC with power connected to the utility grid. It was also the first OTEC located on land that generated net power and hit a record in total production of net power $31.5 \mathrm{~kW}$, with a corresponding gross power of $120 \mathrm{MW}$ (Avery and Wu, 1994). From this data, the total power generation efficiency was calculated to be $31.5 / 120=26 \%$.

\section{Methanol Plantship}

The methanol plantship OTEC design is a conceptual study of a closed-cycle $160 \mathrm{MW}$ plantship designed to use OTEC electrolytic hydrogen and oxygen reacting with coal for the synthesis of methanol on board. The methanol is sent in conventional tankers to ports on the continent, after being accumulated in tanks on board for a month or so. It uses both oxygen and hydrogen efficiently in the process, which could replace gasoline for transport at competitive costs. No carbonic gas is generated as a by-product of the OTEC methanol synthesis process.

Eight modules of $10 \mathrm{MW}$ are allocated around a CWP and eight around another CWP. Seawater supplied by gravity flows from overhead ponds into two condensers and two evaporators that are part of each module of $10 \mathrm{MW}$. The annual average nominal power of the plant is $160 \mathrm{MW}$, but in July and August this power is estimated to be $178.4 \mathrm{MW}$ (net) with maximum output of $189.9 \mathrm{MW}$ (net), according to calculations of the power output for each month. Since the maximum output has been reached, it was proposed the installation of an additional coal-fired boiler electric power system to maintain this constant net power of 189.9 $\mathrm{MW}$ in the methanol plant. This power will be used as net power to calculate the efficiency. The gross power output of the system is $234 \mathrm{MW}$ (Avery and Wu, 1994). According to these 
values, the power generation efficiency of the methanol plantship OTEC is calculated to be $190 / 234=\sim 81 \%$.

\section{Results and Discussion}

Through collection and analysis of data via textbooks accessed through the UTS library and articles accessed via the web, we were able to collate all relevant data together in a table.

The table below summarizes all of the relevant data collected of the above eight OTEC plants.

Table 1. Collection of gross power, net power, and calculated efficiency for all eight OTEC systems discussed above.

\begin{tabular}{|l|l|l|l|l|r|}
\hline & Type & Cycle & $\begin{array}{l}\text { Gross } \\
\text { Power }\end{array}$ & $\begin{array}{l}\text { Net } \\
\text { Power }\end{array}$ & Efficiency \\
\hline US Mini OTEC Program & Real & Closed & $93 \mathrm{KW}$ & $18 \mathrm{KW}$ & $19 \%$ \\
\hline Hawaii Land Based OTEC & Real & Hybrid & $255 \mathrm{KW}$ & $103 \mathrm{KW}$ & $40 \%$ \\
\hline $\begin{array}{l}\text { GE Corporation Shelf Mounted } \\
\text { OTEC }\end{array}$ & Conceptual & Closed & $54.95 \mathrm{KW}$ & $40 \mathrm{KW}$ & $73 \%$ \\
\hline $\begin{array}{l}\text { Puerto Rico Electric Power } \\
\text { Authority }\end{array}$ & Conceptual & Closed & $53 \mathrm{MW}$ & $40 \mathrm{MW}$ & $75 \%$ \\
\hline & & & 15.307 & 100.14 & \\
C.B. Panchal Model & Conceptual & Hybrid & MW & MW & $65 \%$ \\
\hline Claude Ocean Thermal & Conceptual & Open & $100 \mathrm{MW}$ & $45.7 \mathrm{MW}$ & $46 \%$ \\
\hline Japanese Shore-Based OTEC & Real & Closed & $120 \mathrm{KW}$ & $31.5 \mathrm{KW}$ & $26 \%$ \\
\hline Methanol Plantship & Conceptual & Closed & $234 \mathrm{MW}$ & $190 \mathrm{MW}$ & $81 \%$ \\
\hline
\end{tabular}

It can be seen from table 1 that the efficiency is directly proportional to the amount of gross power produced by the OTEC (scale of the plant). The larger the magnitude of the gross power produced by the OTEC, the higher the efficiency. On further investigation, it is hypothesized that this observation is directly related to the depth of the cold water pipe. First the cold water pipe will be discussed, and then related to the size of the OTEC plant.

\subsection{Cold Water Pipe}

Historical evidence suggests that the cold water pipe (CWP) is a very important component of consideration in the construction of an OTEC. This is because, in order to be effective in regards to power production, the CWP must reach depths of at least $1000 \mathrm{~m}$, where the water temperature is cold enough to create large enough temperature gradient to be used 
for the cycle. The necessity for large amounts of cooling water and to minimize pumping power losses results in CWP's with large diameters (Gerard \& Luis, 2002).

Unfortunately, not enough information was accessible on the depths and power usage of all eight systems mentioned in this meta-study. Furthermore, parasitic power used by the cold water pipe pumps for the system which lacked this information, could not be calculated because not enough information was presented. Although the remaining four OTEC systems provide a limited amount of data, they still present useful information and trends. Below is a table of all data that was collected about the depth of the CWP and parasitic power of the cold water pipe pump.

Table 2. Depths of the CWP for four of the OTEC plants discussed above, with the calculated CWPP power usage over the gross power. This calculation demonstrates the parasitic power use of the CWPP relevant to the gross power output.

\begin{tabular}{|l|l|l|l|l|}
\hline & $\begin{array}{l}\text { Depth of CWP } \\
(\mathrm{m})\end{array}$ & $\begin{array}{l}\text { Cold Water Pump } \\
\text { Usage Power } \\
\left(P_{C W P P}\right)\end{array}$ & $\begin{array}{l}\text { Gross output } \\
\text { power of OTEC } \\
\left(P_{\text {Gross }}\right)\end{array}$ & $P_{C W P} / P_{\text {Gross }}$ \\
\hline $\begin{array}{l}\text { Japanese Shore- } \\
\text { Based }\end{array}$ & 670 & $43.3 \mathrm{~kW}$ & $120 \mathrm{~kW}$ & $36 \%$ \\
\hline $\begin{array}{l}\text { GE Corporation } \\
\text { Shelf-Mounted } \\
\text { OTEC }\end{array}$ & 670 & $9.98 \mathrm{MW}$ & $54.95 \mathrm{MW}$ & $18 \%$ \\
\hline $\begin{array}{l}\text { C.B. Panchal } \\
\text { Model }\end{array}$ & 1000 & $2.50 \mathrm{MW}$ & $15.31 \mathrm{MW}$ & $16 \%$ \\
\hline $\begin{array}{l}\text { Methanol } \\
\text { Plantship }\end{array}$ & $25.9 \mathrm{MW}$ & $234 \mathrm{MW}$ & $11 \%$ \\
\hline
\end{tabular}

Although the depth of the Methanol Plantship CWP was not accessible, from trends in relation to the depth of CWP and gross power output of the other OTEC systems (see appendix B) it can be assumed that the depth of the Methanol Plantship CWP was between 670-1000 m.

We see from the table that the proportion of the parasitic power of the CWP over the magnitude of the gross power output decreases as the gross power output of the plant increases. This meta-study hypothesizes that the reason for this trend is directly related to the depth of the cold water pipe.

Reasoning from the above statement: that in order to be effective the CWP must reach depths of at least $1000 \mathrm{~m}$, it follows that the power used by the cold water pump would remain roughly constant for each OTEC system, independent of gross output power. Rewriting equation (1) as

$$
P_{N}=P_{G}-P_{\text {wasted }}-P_{C W P P}
$$


where $P_{\text {wasted }}$ refers to all parasitic power sites excluding the cold water pipe pump and $P_{C W P P}$ refers to power usage of the cold water pipe pump, we notice that if $P_{C W P P}$ remains roughly the same for all effective OTEC plants (due to the effective depth), and $P_{G}$ varies, then $P_{N}$ varies only with the magnitude of $P_{G}$. Hence if we look back at equation (2), we see for OTEC plants with a smaller output gross power, the efficiency will be inferior to that of an OTEC plant with a larger gross power output. However, from table 2, we notice that two of the plants used a CWP which reached a depth of $670 \mathrm{~m}$. Although in contradiction with the above statement (1000 $\mathrm{m}$ is a minimum depth for effective overall efficiency), the two OTEC systems offer directly comparable data, as they have a common CWP depth, but significantly different gross power outputs. From table 2, it is evident that the General Electric Shelf-Mounted OTEC is superior to the Japanese-Shore based OTEC in terms of the amount of power used by the CWPP in comparison to the gross power output. Both OTEC plants are closed cycle, however the General Electric OTEC is conceptual. From this data, it can be concluded that a possible reason that efficiency is proportional to the gross power output of the OTEC is due to the fact that the gross power of the OTEC is independent of the CWP depth, however, the net power output is not. This leads to the parasitic power usage of the plant not varying sufficiently to justify constructing a smaller plant with small gross power.

\section{Conclusions}

The results and discussions presented in this meta-study have come about through a detailed search using a number of different sources. The most helpful sources proved to be two textbooks accessed via the UTS library website, and various online OTEC proposals accessed via the web, with databases proving unhelpful.

From the results presented in this meta-study it can be concluded that as the plants gross output power increases, the more efficient that OTEC is. As the power used to pump the cold water up the pipe does not vary significantly according to the magnitude of the gross power, the ratio of the $\boldsymbol{P}_{\boldsymbol{C W P P}} / \boldsymbol{P}_{\boldsymbol{G}}$ varies significantly according to $\boldsymbol{P}_{\boldsymbol{G}}$. Therefore, larger scale OTEC plant sizes are more efficient in terms of power generation than smaller scale OTEC plants.

\section{References and Notes}

1. Anon, (2015). [online] Available at: <http://www.cres.gr/kape/education/3.CHP_en_small.pdf> [Accessed 23 May 2015].

2. Avery, W. and Wu, C. (1994). Renewable energy from the ocean. New York, NY [u.a.]: Oxford Univ. Press.

3. Clubdesargonautes.org, (2015). IOA Newsletter vol.12 No.4/Winter 2001. [online] Available at: <http://www.clubdesargonautes.org/otec/vol/vol12-4-2.htm> [Accessed 18 May 2015].

4. En.openei.org, (2015). Marine and Hydrokinetic Technology Glossary I Open Energy Information. [online] Available at:

<http://en.openei.org/wiki/Marine_and_Hydrokinetic_Technology_Glossary> [Accessed 9 May 2015]. 
5. Energy.gov, (2015). Ocean Thermal Energy Conversion Basics. [online] Available at: <http://energy.gov/eere/energybasics/articles/ocean-thermal-energy-conversion-basics> [Accessed 11 May 2015].

6. Gerard. C, Luis. A, , 2002, 'Design of a 5 MWe OTEC Pre-Commercial Plant', Pacific International Centre for High Technology Research 2800 Woodlawn Dr., Honolulu, Hawaii (USA) pp.2.

8. Hagen, A. (1975). Thermal energy from the sea. Park Ridge, N.J.: Noyes Data Corp.

9. Oceanica.ufrj.br, (2015). [online] Available at: <http://www.oceanica.ufrj.br/labeco/combustao/materiais/Mar_Energia2009a> [Accessed 23 May 2015].

10. Renewable Energy Journal, (2007). Thermal energy harvest. [online] Available at: <http://montaraventures.com/energy/?p=135> [Accessed 24 May 2015].

11. Schulte, J. 2015, 'Thermodynamic process', UTS Online Subject 68412, lecture notes, UTS, Sydney, viewed 18 April 2015, <https://online.uts.edu.au/bbcswebdav/pid-1064639-dtcontent-rid-5902017_1/courses/68412/EST_ThermoDynamics1a.pdf>

12. Vega, 2002, Published in Marine Technology Society Journal V. 6, No. 4 Winter 2002/2003 pp. 25-35.

13. Web.mit.edu, (2015). 8.5 Rankine Power Cycles. [online] Available at: <http://web.mit.edu/16.unified/www/FALL/thermodynamics/notes/node65.html>[Accessed 19 May 2015].

14. Wiley.com, (2015). ThermoNet. [online] Available at: <http://www.wiley.com/college/moran/CL_0471465704_S/user/tutorials/tutorial10/tut10b_pa rent.htm> [Accessed 22 May 2015].

\section{Appendix A: The Rankine cycle}

The Rankine cycle is more conventionally used in combustion mechanisms, and its success is due to the amount of energy which is recovered in re-pressurizing the vapor back into liquid. However in the case of the closed-cycle OTEC, a substantial amount of energy is lost in the process of pumping cold sea water (up to $1000 \mathrm{~m}$ below the surface of the water) into the condenser. Although this loss of energy is seemingly large, it is reduced by the natural hydrostatic pressure gradient, which makes up a large portion of the increase in gravitational potential energy of a fluid travelling with the gradient from deep water to the surface.

Below are two diagrams of the temperature-entropy for both Rankine and Carnot cycle in closed-cycle OTEC's.

Figure A.1. a) on the left is the temperature-entropy (TS) diagram for the Rankine cycle followed by b) the TS diagram for the Carnot cycle on the right (Wiley.com, 2015). 


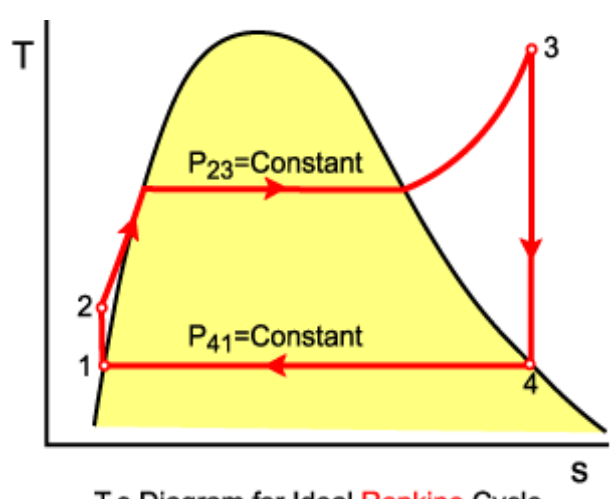

T-s Diagram for Ideal Rankine Cycle

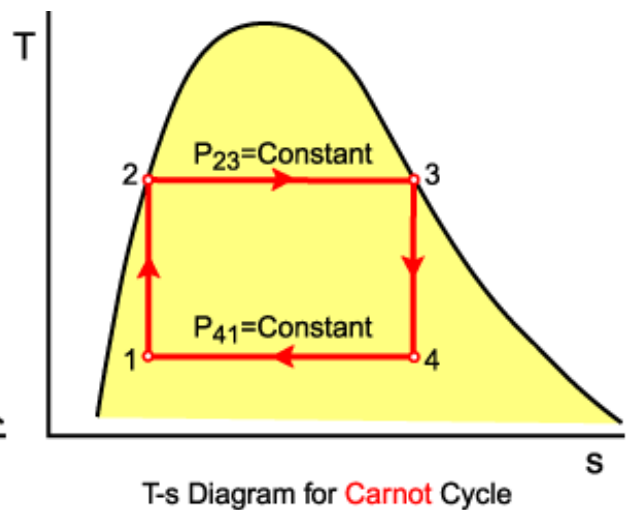

Analyzing the T-s diagram for Carnot Cycle:

1-2: Isentropic compression (Pump).

High pressure could cause serious damages to the pump. Extremely tough materials would be necessary in order to resist elevated pressures.

According to the Hydraulics, a biphasic mixture causes low efficiency of the pump.

2-3: Isothermal heating.

3-4: Isentropic expansion (Turbine).

Mixture: vapor and liquid. The liquid appears in drops. These drops could cause the erosion of the turbine.

4-5: Isothermal cooling.

Due to the issues regarding the Carnot Cycle, the Rankine cycle is the applicable choice for heat engines such as the Ocean Thermal Energy Conversion power plant.

\section{Appendix B}

Table B.1. Depth of CWP and corresponding gross power output for five OTEC systems (Avery and Wu 1994).

\begin{tabular}{|l|l|l|}
\hline & CWP depth (m) & Gross Power \\
\hline US Mini-OTEC Program & 670 & $93 \mathrm{~kW}$ \\
\hline $\begin{array}{l}\text { GE Corporation Shelf-Mounted } \\
\text { OTEC }\end{array}$ & 670 & $54.95 \mathrm{MW}$ \\
\hline $\begin{array}{l}\text { Puerto Rico Electric Power } \\
\text { Authority }\end{array}$ & 1000 & $53 \mathrm{MW}$ \\
\hline C.B. Panchal Model & 1000 & $15.31 \mathrm{MW}$ \\
\hline Japanese Shore-Based & 670 & $120 \mathrm{~kW}$ \\
\hline
\end{tabular}

